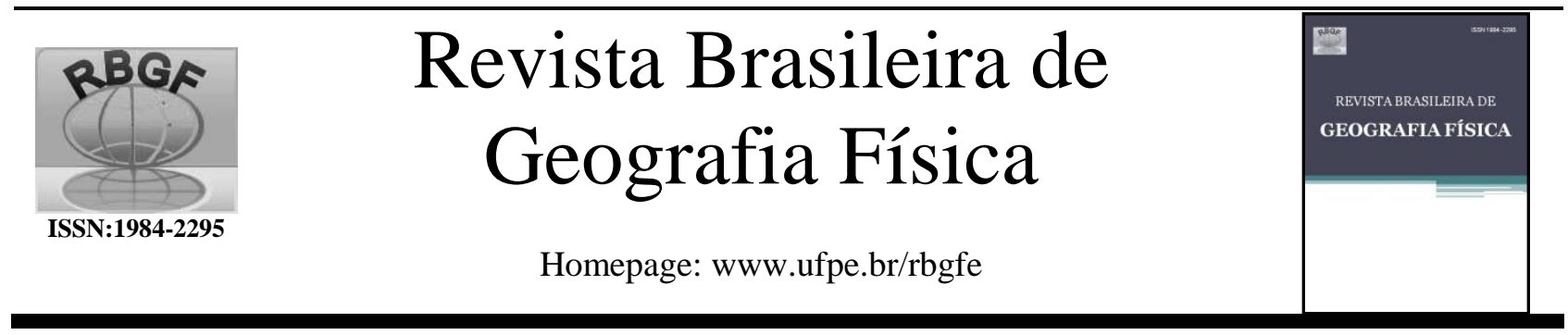

\title{
O valor de uso direto (VUD) dos serviços ambientais de regulação no Parque da Jaqueira (Recife, Pernambuco)
}

\begin{abstract}
Josimar Vieira dos Reis ${ }^{1}$, Jadson Freire da Silva ${ }^{2}$, Rutt Keles Alexandre da Silva ${ }^{3}$, Thomas Henrique de Holanda ${ }^{4}$,
\end{abstract} Pamela Barcelar Ferreira Gomes da Silva ${ }^{5}$, Elisabeth Regina Alves Cavalcanti Silva ${ }^{6}$

\begin{abstract}
${ }^{1}$ Doutorando em Desenvolvimento Urbano(UFPE), Recife, Pernambuco, Brasil; prej86@gmail.com; ${ }^{2}$ Doutorando em Desenvolvimento e Meio Ambiente (UFPE), Recife, Pernambuco Brasil; jadsonfreireufpe@hotmail.com; ${ }^{3}$ Mestra em Desenvolvimento e Meio Ambiente (UFPE), Recife, Pernambuco Brasil; kelesrutt@hotmail.com; ${ }^{4}$ Graduando em Geografia (UFPE), Recife, Pernambuco Brasil; thomas.holanda@hotmail.com; ${ }^{5}$;Mestranda em Engenharia Química (UFPE), Recife, Pernambuco, Brasil:pamelabarcelar@gmail.com ${ }^{6}$ Doutoranda em Desenvolvimento e Meio Ambiente, Recife, Pernambuco Brasil (UFPE); elisabeth.silva@ifma.edu.br
\end{abstract}

Artigo recebido em 04/02/2018 e aceito em 30/06/2018

\section{RESUMO}

Este artigo visa apresentar o resultado da identificação do Valor de Uso Direto (VUD) dos serviços ambientais de regulação do parque da Jaqueira, na cidade do Recife-PE, no bairro Homônimo. Através da aplicação de 133 questionários entre os dias 14 a 23 de dezembro de 2017. O questionário continha uma estrutura socioeconômica e uma pergunta relacionada com Disposição A Pagar (DAP) sobre os serviços ambientais regulação, junto a um pequeno guia explicativo sobre o que são serviços ambientais e qual a sua influência na vida do ser humano, que era lido para o participante. Após a conclusão de toda a coleta os dados foram tabulados em planilhas no software Microsoft Excel 2016 para facilitar a importação para o programa que foi usado na análise estatística o SPSS - Statistical Package f o r S o c i a 1 Sciences SPSS versão 20 2011. Onde é possível obter a probabilidade P(Y) de um entrevistado apresentar aquela característica de interesse (ex: não estar disposto a pagar) com base nas suas informações como Renda $\left(\mathrm{X}_{1}\right)$, Escolaridade (X2). Para todos os testes estatísticos utilizou-se do nível de 5\% de significância. Trazendo como resultado o valor de dez Reais sobre o VUD dos serviços ambientais de regulação do parque da Jaqueira.

Palavras-chave: Valor de Uso Direto (VUD), Serviços ambientais, Estatística.

\section{The value of direct use (VDU) of environmental regulation services in Jaqueira Park (Pernambuco - Brazil)}

\begin{abstract}
A B S T R A C T
This article aims to present the result of the identification of the Direct Use Value (DUV) of the environmental regulatory services of the Jaqueira Park, in the city of Recife - Pernambuco (Brazil), in the neighborhood of the same name. Through the application of 133 questionnaires from December 14 to 23, 2017. The questionnaire contained a socioeconomic structure and a question related to Disposal to Pay (DTP) on environmental services regulation, along with a small guide explaining what environmental services and what their influence on human life. After completing the entire data collection the data were tabulated in spreadsheets in Microsoft Excel 2016 software to facilitate the import into the program that was used in statistical analysis SPSS - Statistical Package for Social Sciences SPSS version 202011 . Where it is possible to obtain the probability $\mathrm{P}(\mathrm{Y})$ of a respondent to display that characteristic of interest (eg not being willing to pay) based on their information such as Income (X1), Schooling (X2). For all statistical tests, the 5\% level of significance was used. Bringing as a result the value of R \$ 10.00 Reais on the VUD of the environmental services of regulation of the park of Jaqueira.
\end{abstract}

Keywords: Direct Use Value (DUV), Environmental Services, Statistic.

\section{Introdução}

Desde as primeiras cidades construídas e urbanizadas pelo homem ao longo do tempo observou-se o uso comum dos espaços de convivências como, por exemplo, as áreas de lazer. Esses locais foram adquirindo diversas formas de uso pelas populações, como os largos, arenas, as praças e os parques, que serviam para descanso, passeios ou até para negócios, deste modo, 
verificou-se que os espaços públicos comumente estão em áreas principais e centrais de diversas cidades do mundo; onde estas são arborizadas e tem um valor muitas vezes de sentimento e pertencimento, como uma marca da população a qual pertence.

As primeiras iniciativas por espaços naturais voltados para a recreação tiveram decorrência do processo de urbanização das cidades, aglomeração demográfica nos centros urbanos e crescimento maciço da atividade industrial, modificando assim, grande parte da paisagem natural para a urbana.

Sobre a paisagem urbana Zukin (2000) a define como uma construção material, mas também uma representação simbólica das relações sociais e espaciais. Malamut (2014) acrescenta que a paisagem é tudo aquilo que está ao alcance do olhar do observador, e, no meio urbano, é consequência da interferência humana sobre o espaço natural, no qual passa a fazer parte dela as intervenções urbanísticas, as edificações, a vegetação como os parques.

A primeira referência de parque segundo Araújo (2012) foi o de Parque Nacional de Yellowstone nos Estados Unidos data de 1876 a primeira proposição para a criação no mundo para fins de conservação.

Hoje a dinâmica e o modo de vida do ser humano está em frenético agito, seja por trabalho ou outros afazeres diários do homem moderno, que nem sempre proporciona tempo ao indivíduo de usufruir de espaços públicos coletivos como os parques e praças, nem por isso, esses locais perderam a sua importância, sendo usado, para o lazer das crianças e práticas esportivas de quem o procura. Ressalta-se a importância dessas áreas na conservação das áreas verdes, que regula o microclima local, deixando espaços com muitas sombras, interagindo com o meio urbano e tentando sobreviver ao aumento das cidades e sua verticalização.

Os parques com áreas verdes podem constituir benefícios para o ambiente urbano, como apontam Macedo e Robba (2002) ao destacarem o uso da vegetação, tanto com apelo estético como fator de amenização climática e os aspectos subjetivos relacionados à sua existência, como a influência positiva no psicológico da população, proporcionada pelo contato com a área verde e/ou pelo uso do espaço para o convívio social. Segundo os autores, tais benefícios estão vinculados a valores ambientais, funcionais e estéticos/simbólicos.

Para Lima Junior (2012), estas novas práticas do urbanismo e do planejamento urbano e os conceitos e representações a elas associados evidenciam uma mudança de mentalidade no que diz respeito à cidade as suas áreas verdes, apesar de autores como Silva et al. (2017) salientarem a relação conflituosa, entre o desenvolvimento urbano e a conservação de ambientes naturais.

As áreas das cidades, principalmente os espaços verdes vem perdendo importância dentro do cenário urbano com o seu mercado imobiliário que se expande em todas as direções sem pensar no meio ambiente. Sendo assim Costa (2003) acredita que, como boa parte das grandes cidades brasileiras vem passando por transformações muito rápidas e sem controle, correndo o risco de também perder seus lugares tão importantes para a consolidação dos vínculos coletivos para a especulação e apropriação imobiliária.

Para Leal (2016) os impactos muitas vezes danosos sobre os espaços físico, social e ambiental, contribuíram para a consolidação de mudanças na dinâmica espacial, principalmente em áreas verdes urbanas como os parques.

Campos (2007) explana que a apropriação imobiliária nos espaços representa hoje, para o mercado capitalista empreendedor, desafios entre a incorporação da modernidade urbanística e a necessidade de conservação do ambiente natural. Sendo assim, os parques se tornaram espaços que devem ser conservados dentro de uma cidade por trazer inúmeros benefícios, principalmente em relação a regulação do clima em torno dos bairros. Para Rech (2011) a conservação das paisagens naturais urbanas, trazem o equilílibrio climático, o conforto térmico e na maior parte dependem de implementação de práticas humanas que miniminizem os impactos adverso nesses ecosistemas.

Nestes parques ocorrem diversas interações biológicas, resultando em importantes processos naturais que garantem a sobrevivência de algumas espécies da fauna e da flora que se adaptaram e têm a capacidade de prover serviços que satisfaçam direta e indiretamente as necessidades do homem e se apresentam como serviços ambientais. Em relação aos serviços ambientais.

Autores como Guedes e Seehusen (2011) entendem serviços ambientais e ecossistêmicos são sinônimos. Já Tôsto et al. (2012), diferenciam estes dois tipos de serviços: para estes autores, serviços ecossistêmicos são os benefícios diretos e indiretos providos pelo funcionamento dos ecossistemas, sem a interferência humana; já os serviços ambientais são os benefícios gerados por ações de manejo do homem nos sistemas naturais ou agroecossistemas, o que serviria para manter a oferta de serviços ecossistêmicos pela natureza. 
Diante das diferenciações no campo acadêmico, o conceito de serviço ambiental ou ecossistêmico mais aceito pelos pesquisadores é o desenvolvido pelas Organizações das Nações Unidas (ONU) muito bem resumido no relatório da Avaliação Ecossistêmica do Milênio (EAM, 2005), que classifica os serviços prestados pela Natureza em Serviços de Suporte (reciclagem dos nutrientes, produção primária, formação e retenção do solo, provisão de habitat e gerenciamento de lixo), Aprovisionamento (produtos obtidos diretamente dos ecossistemas - alimento, água, fibras, plantas medicinais), de Regulação (benefícios obtidos da regulação dos ecossistemas - regulação climática, manutenção e purificação da qualidade de ar) e Culturais (benefícios não-materiais obtidos através do uso do ecossistema - lazer, beleza cênica, ecoturismo, etc).

Dificilmente é observado um serviço ambiental sendo prestado isoladamente, isto quer dizer que as áreas conservadas, por exemplo, fornecem inúmeros serviços interligados entre si, como: conservação da biodiversidade, contribuição para a melhoria do corpo hídrico, manutenção da ciclagem de nutrientes, regulação do microclima, dentre outros. Entretanto, nem sempre é possível haver clara delimitação do serviço.

Altmann e Rech (2009) afirmam que para a natureza prestar corretamente os serviços ambientais e preciso que esteja em um bom estado de preservação. Para Constanza (2008) esta é uma boa definição de serviços ambientais, uma vez que é geral o bastante, apropriadamente vaga e engloba tanto os serviços percebidos pelas pessoas (alimentos, fibras etc.) como também aqueles não percebidos (controle de erosão do solo, por exemplo). $\mathrm{O}$ autor ainda afirma que a maioria dos serviços ambientais não é percebida por seus beneficiários.

De acordo com Nusdeo (2012) os serviços ambientais são variados como a polinização natural, a ciclagem de nutrientes do solo, a manutenção do volume e qualidade dos recursos hídricos e o sequestro de carbono, que permite a estabilização climática.

Dada a importância dos serviços ambientais, este artigo teve como objetivo identificar o Valor de Uso Direto (VUD) dos serviços ambientais de regulação (regulação climática, manutenção e purificação da qualidade do ar) do parque da Jaqueira, na cidade do RecifePE, no bairro homônimo. Além disso, a presença dessa área no ambiente urbano insere a sociedade no contexto das preocupações com a conservação do meio ambiente induzindo-as voluntariamente a refletirem sobre a importância de se constituir espaços de conservação dentro dos meios urbanos.

\section{Material e métodos}

Para alcançar o referido objetivo este artigo foi estruturado por meio de uma pesquisa bibliográfica e documental acerca dos serviços ambientais, dos benefícios sociais e ambientais gerados. Com este propósito, foram realizadas visitas ao parque da Jaqueira para a aplicação dos questionários entre seus frequentadores. Utilizando o Método de Valoração Contingente (MVC) sobre a Disposição A Pagar (DAP) dos seus frequentadores sobre o VUD dos serviços ambientais de regulação do parque da Jaqueira. Tendo em consideração que o teste estatístico escolhido foi a regressão logística binária. A aplicação dessa abordagem pode colaborar com reconhecimento do valor da sociedade como agente transformador capaz de notar o ambiente e como ele está inserido neste contexto, e entender as dinâmicas ambientais através da vivência é interação do ambiente urbano com o ecossistema.

\section{Caracterização da Área}

O parque da Jaqueira está localizado no bairro homônimo, na zona norte da cidade do Recife, no Estado de Pernambuco. Inserido em uma das áreas mais nobres da cidade é circundado por uma densa urbanização, edificações e avenidas de intenso fluxo de veículos. Conforme a Figura 01. O parque da Jaqueira teve sua inauguração em 1985 e, é o segundo maior parque público da cidade do Recife com $70.000 \mathrm{~m}^{2}$ sendo o maior parque da cidade o da Macaxeira. O parque é utilizado como área de lazer, possui pistas de cooper, bicicross, e áreas de diversão para crianças. 


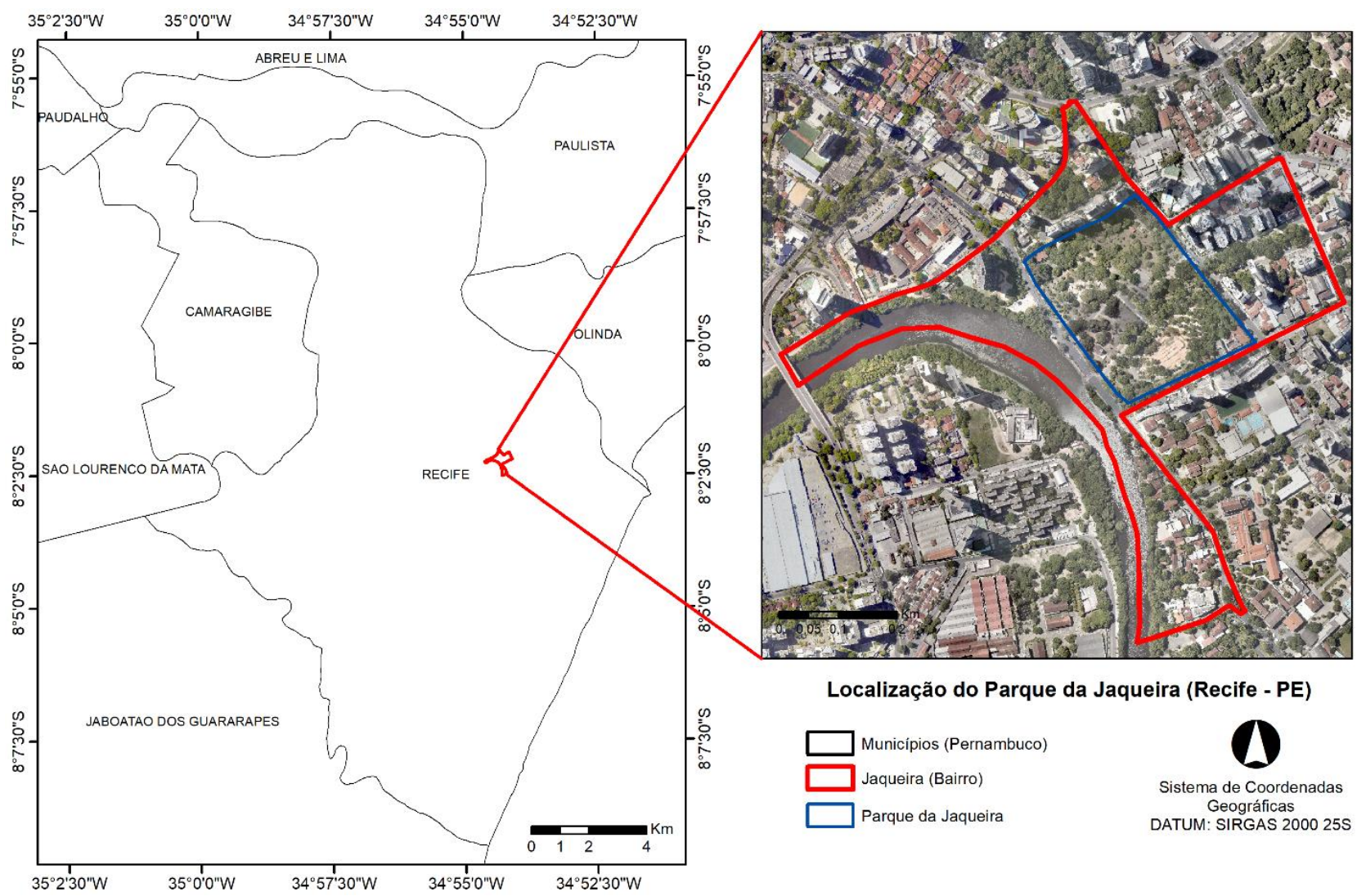

Figura 1 - Localização do parque da Jaqueira, Recife - PE.

\section{Procedimentos metodológicos}

Foram aplicados 133 questionários sobre valoração dos serviços ambientais de regulação aos frequentadores do parque da Jaqueira entre os dias 14 a 23 de dezembro de 2017 nos períodos manhã e tarde, com uma equipe de três pessoas, onde ressalta-se o grande número de visitantes devido ao período de férias. $\mathrm{O}$ perfil escolhido para participar da aplicabilidade do questionário foram pessoas na idade de 18 anos a até 65 anos, respeitando a escolha pirâmide etária com base no índice de População Economicamente Ativa - PEA. Sobre o PEA, todo país, seja subdesenvolvido ou desenvolvido, possui uma População Economicamente Ativa (PEA), que é uma parcela do contingente populacional e representa todas as pessoas que trabalham ou que estão procurando emprego, de acordo com Freitas (2016) no caso específico do Brasil, a PEA soma aproximadamente 79 milhões de pessoas.

O questionário foi dividido nas seguintes partes: 1) informações socioeconômicas (idade; gênero; local onde reside; escolaridade; renda mensal) 2) Informação DAP (Disposição A Pagar) sobre os serviços ambientais de regulação, existentes no parque da Jaqueira, totalizando seis perguntas no questionário.

O meio de eliciação da DAP foi definido como sendo a referendum com jogos de leilão (bidding-games). Desta maneira, existe a necessidade de um valor inicial/ponto de partida para a DAP caso o entrevistado estivesse disposto a pagar alguma quantia. Conforme o Quadro 1.

Quadro 1. Valores DAP utilizados (em R\$)

\begin{tabular}{|c|c|c|c|c|c|c|c|}
\hline $\mathbf{0 1}$ & $\mathbf{0 2}$ & $\mathbf{0 3}$ & $\mathbf{0 4}$ & $\mathbf{0 5}$ & $\mathbf{0 6}$ & $\mathbf{0 7}$ & $\mathbf{0 8}$ \\
\hline $\mathrm{R} \$ 2,00$ & $\mathrm{R} \$ 5,00$ & $\mathrm{R} \$ 10,00$ & $\mathrm{R} \$ 15,00$ & $\mathrm{R} \$ 20,00$ & $\mathrm{R} \$ 25,00$ & $\begin{array}{l}\text { Mais que } \\
\mathrm{R} \$ 30,00\end{array}$ & Não sei \\
\hline
\end{tabular}

Por fim, aplicou-se uma análise multivariada por meio da Regressão Logística
Binária. Segundo Fávero et al. (2009) em 1960, essa técnica foi desenvolvida para investigar a 
relação entre variáveis explicativas, métricas e não métricas e uma variável dependente categórica binária. Neste sentido, o uso da regressão logística binária tem como objetivo de verificar quais as variáveis ou fatores que influenciou o entrevistado na decisão de não estar disposto a pagar por serviços ambientais na localidade, sendo estão "não" o nosso desfecho de interesse $(Y=1)$. Nesta etapa foram aplicados testes individuais dos parâmetros com o objetivo de verificar se cada variável em particular seria significativa ( $\mathrm{p}$-valor $<0,05)$ para o aumento $(\mathrm{B}>0)$ ou diminuição $(\mathrm{B}<0)$ da probabilidade de o indivíduo não estar disposto a pagar. Por outro lado, as variáveis independentes foram Estação/Período de Coleta; Faixa Etária; Gênero; Localidade; Escolaridade e Faixa de Renda. O modelo aplicado é mostrado a seguir (equação 1):

$$
P(Y)=\frac{1}{1+e^{-\left(b_{0}+b_{1} X_{1}+b_{2} X_{2}+b_{3} X_{3}+b_{4} X_{4}+b_{5} X_{5}+b_{6} X_{6}\right)}}(1)
$$

Onde, baseando-se nas informações de Estação/Período de Coleta $\left(\mathrm{X}_{1}\right)$, Faixa Etária $\left(\mathrm{X}_{2}\right)$, Gênero $\left(\mathrm{X}_{3}\right)$, Localidade $\left(\mathrm{X}_{4}\right)$, Escolaridade $\left(\mathrm{X}_{5}\right)$ e Faixa de Renda $\left(\mathrm{X}_{6}\right)$ é possível obter a probabilidade $\mathrm{P}(\mathrm{Y})$ de um entrevistado não pagar. Os valores dos betas (b) representam a contribuição de cada variável ou conhecidos como as estimativas dos parâmetros do modelo.

Os resultados foram tabulados no software Microsoft Excel 2016 para facilitar a importação das planilhas para o programa a ser usado na análise estatística. A literatura

\section{Resultados e discussão}

Os resultados da Tabela 1 mostram que $(35,3 \%)$ dos entrevistados tinham entre 25 e 34 anos, e $(27,8 \%)$ entre 35 e 44 anos, levando a concluir que $(63,1 \%)$ dos entrevistados possuíam entre 25 e 44 anos.

Em relação ao gênero, obteve-se $(51,9 \%)$ de entrevistados do sexo feminino e $(48,1 \%)$ do sexo masculino, mostrando assim haver homogeneidade da amostra em relação ao sexo. As pessoas do gênero feminino demonstraram maior interesse sobre os serviços ambientais de regulação e sensibilidade sobre o ambiente. econométrica apresenta alguns modelos capazes de tais predições a respeito da probabilidade de um evento acontecer ou não.

Para a análise de dados utilizou-se o software SPSS - Statistical Package f o r S o c i a 1 Sciences SPSS versão 20 2011, onde com base numa amostra de 133 entrevistados, inicialmente traçou-se o perfil da amostra a partir do estudo das frequências absolutas e percentuais para cada uma das variáveis do estudo.

Para o local de residência, obteve-se que grande parte $(64,6 \%)$ dos entrevistados eram moradores da Zona Norte $(39,8 \%)$ região do parque ou do bairro da Jaqueira $(24,8 \%)$ e apenas $(27 \%)$ de outras Zonas da cidade. Além disto, notou-se que $(38,3 \%)$ dos entrevistados informaram ter ensino médio e $(32,2 \%)$ com nível superior.

Sobre a renda familiar mensal, verifica-se uma maior concentração $(30,1 \%)$ dos frequentadores com renda familiar entre $\mathrm{R} \$ 937,00$ a $\mathrm{R} \$ 1.874,00$ e também um relevante percentual $(20,3 \%)$ de entrevistados com renda acima de R \$ $3.749,00$. Nota-se ainda que apenas $(13,5 \%)$ dos entrevistados possuíam renda familiar abaixo de $\mathrm{R} \$ 937,00$. A maioria das pessoas com renda até um salário é de outras zonas da cidade.

Tabela 1. Distribuição das frequências simples e percentuais para a Faixa Etária, Gênero, Local de Residência, Escolaridade e Renda familiar dos frequentadores

N $\%$




\begin{tabular}{|c|c|c|}
\hline \multicolumn{3}{|l|}{ Faixa Etária } \\
\hline 18 a 24 anos & 16 & $12,0 \%$ \\
\hline 25 a 34 anos & 47 & $35,3 \%$ \\
\hline 35 a 44 anos & 37 & $27,8 \%$ \\
\hline 45 a 54 anos & 19 & $14,3 \%$ \\
\hline 55 a 65 anos & 14 & $10,5 \%$ \\
\hline \multicolumn{3}{|l|}{ Gênero } \\
\hline Masculino & 64 & $48,1 \%$ \\
\hline Feminino & 69 & $51,9 \%$ \\
\hline \multicolumn{3}{|l|}{ Local de Residência } \\
\hline Morador da Zona Norte & 32 & $24,1 \%$ \\
\hline Morador do Bairro da Jaqueira & 33 & $24,8 \%$ \\
\hline Morador de outras Zonas da Cidade do Recife & 53 & $39,8 \%$ \\
\hline Morador de outras Cidades/Estado & 15 & $11,3 \%$ \\
\hline \multicolumn{3}{|l|}{ Escolaridade } \\
\hline Fundamental Incompleto & 5 & $3,8 \%$ \\
\hline Fundamental & 8 & $6,0 \%$ \\
\hline Médio Incompleto & 3 & $2,3 \%$ \\
\hline Médio & 51 & $38,3 \%$ \\
\hline Curso técnico & 6 & $4,5 \%$ \\
\hline Curso superior & 43 & $32,2 \%$ \\
\hline Pós-graduado & 17 & $12,8 \%$ \\
\hline \multicolumn{3}{|l|}{ Renda pessoal } \\
\hline Abaixo de $\mathrm{R} \$ 937,00$ & 18 & $13,5 \%$ \\
\hline $\mathrm{R} \$ 937,00$ a $\mathrm{R} \$ 1.874,00$ & 40 & $30,1 \%$ \\
\hline $\mathrm{R} \$ 1.875,00$ a $\mathrm{R} \$ 2.811,00$ & 21 & $15,8 \%$ \\
\hline $\mathrm{R} \$ 2.812,00$ a $\mathrm{R} \$ 3.748,00$ & 27 & $20,3 \%$ \\
\hline Maior que $\mathrm{R} \$ 3.749,00$ & 27 & $20,3 \%$ \\
\hline
\end{tabular}

Destaca-se que antes da aplicabilidade dos questionários, era explicado aos frequentadores que concordaram em participar da aplicação dos mesmos, sobre o que era os serviços ambientais de um modo geral dando destaque aos de regulação: Valor de Uso Direto (VUD) e Disposição A Pagar (DAP), deixando-os esclarecidos sobre os temas abordados durante a aplicação do questionário.

Quando questionados se estariam dispostos a pagar pela conservação dos serviços ambientais de regulação no parque da Jaqueira, $(75,2 \%)$ responderam que "Sim", contra $(24,8 \%)$ que "não". Dos dispostos a pagar, (20\%) informaram pagar $\mathrm{R} \$ 10,00$ e (18\%) dispostos a pagar $\mathrm{R} \$ 15,00$. Neste caso, o valor mais adequado para uma possível seria o de $\mathrm{R} \$ 10,00$, como mostra a tabela 02 a seguir. De acordo com Braga (2009) os subsídios devem estimular iniciativas produtivas de uso sustentável, que garantam a conservação ambiental. Neste sentido o valor atribuído pelos frequentadores deve ser empregado exclusivamente na melhoria do ecossistema do parque, caso aconteça uma política pública para isso.

Tabela 2. Disposição a pagar pelos serviços ambientais de regulação do parque da Jaqueira

$\mathrm{N} \%$




\begin{tabular}{lrr}
\hline $\begin{array}{l}\text { Você estaria disposto a pagar pela conservação dos serviços ambientais } \\
\text { de regulação do parque da Jaqueira? }\end{array}$ & & \\
Sim & 100 & $75,2 \%$ \\
Não & 33 & $24,8 \%$ \\
Quanto você está disposto a pagar? & & \\
R \$ 2,00 & 11 & $11,0 \%$ \\
$R \$ 5,00$ & 13 & $13,0 \%$ \\
$R \$ 10,00$ & 20 & $20,0 \%$ \\
$R \$ 15,00$ & 18 & $18,0 \%$ \\
$R \$ 20,00$ & 14 & $14,0 \%$ \\
$R \$ 25,00$ & 11 & $11,0 \%$ \\
Mais que R\$ 30,00 & 12 & $12,0 \%$ \\
Não sei & 1 & $1,0 \%$ \\
\hline
\end{tabular}

Os 100 frequentadores $(75,2 \%)$ que disseram sim pra DAP informaram que é importante a conservação de áreas verdes dentro das cidades e que os órgãos públicos deveriam legalizar mais áreas verdes dentro dos perímetros urbanos, já que foi unânime entre os frequentadores entrevistados que a procura pelo parque da Jaqueira se dá principalmente pela a interação com a natureza.

Um valor bem próximo àquele encontrado nos estudos de Viana (2009) e Morgado et al. (2011) no qual 55,78\% dos entrevistados manifestaram estarem dispostos a pagar pelo uso do Parque Ecológico Olhos D'Água no Distrito Federal (Viana, 2009). Morgado et al. (2011) verificou em um determinado parque em Brasília que os frequentadores pagariam uma média mensal de $\mathrm{R} \$ 11,59$, respectivamente.

Entre os que disseram não pra DAP sobre os serviços ambientais de regulação, a negativa mais comum foi a alta carga tributária já paga, a não confiança de verbas em mãos de gestores públicos ou em afirmar que é obrigação apenas do Estado e dever de zelar ou prover medidas em prol do meio ambiente.
Com o objetivo de analisar o efeito de alguns fatores sobre o valor disposto a pagar, foi realizado cruzamentos de dados para uma análise dos percentuais, bem como a aplicação do teste Qui-quadrado de Independência e Análise de Correspondência. Os resultados dos testes descritos anteriormente.

Mostraram que a faixa etária influencia significativamente ( $\mathrm{p}$-valor $<0,05)$ o DAP, onde $(54,6 \%)$ dos mais jovens (18 a 24 anos) estão dispostos a pagar $\mathrm{R} \$ 20,00(27,3 \%)$ ou $\mathrm{R} \$ 25$ (27,3\%). Entrevistados com idades entre 45 e 54 anos, estão dispostos a pagar mais $(42,8 \%$ para $\mathrm{R} \$ 25,00$ ou Mais que $\mathrm{R} \$ 30,00$ ) e os mais idosos (55 a 65 anos) tendem a pagar $\mathrm{R} \$ 15,00$. A Tabela 3 aponta os resultados com maior esclarecimento.

Em relação ao gênero, os resultados explanam que a disposição a pagar do entrevistado independe ( $p$-valor $>0,05$ ) do gênero, conforme a Tabela 4. Sendo assim, a sensibilidade e obrigação de manter um meio ambiente equilibrado não advêm sobre as questões de gênero, mostrando desta forma que o ser humano sabe da importância dos ecossistemas e do ambiente que os circunda. 


\begin{tabular}{|c|c|c|c|c|c|c|c|c|c|}
\hline & & & \multicolumn{5}{|c|}{ Faixa Etária } & \multirow[t]{2}{*}{ Total } & \multirow[t]{2}{*}{ p-valor } \\
\hline & & & $\begin{array}{c}18 \text { a } 24 \\
\text { anos }\end{array}$ & $\begin{array}{c}25 \text { a } 34 \\
\text { anos }\end{array}$ & $\begin{array}{c}35 \text { a } 44 \\
\text { anos }\end{array}$ & $\begin{array}{c}45 \text { a } 54 \\
\text { anos }\end{array}$ & $\begin{array}{c}55 \text { a } 65 \\
\text { anos }\end{array}$ & & \\
\hline \multirow[t]{16}{*}{ DAP } & $\mathrm{R} \$ 2,00$ & $\mathrm{~N}$ & 0 & 7 & 1 & 1 & 2 & 11 & 0,048 \\
\hline & & $\%$ & $0,0 \%$ & $20,6 \%$ & $3,4 \%$ & $7,1 \%$ & $16,7 \%$ & $11,0 \%$ & \\
\hline & $\mathrm{R} \$ 5,00$ & $\mathrm{~N}$ & 2 & 2 & 7 & 0 & 2 & 13 & \\
\hline & & $\%$ & $18,2 \%$ & $5,9 \%$ & $24,1 \%$ & $0,0 \%$ & $16,7 \%$ & $13,0 \%$ & \\
\hline & $\mathrm{R} \$$ & $\mathrm{~N}$ & 0 & 7 & 9 & 2 & 2 & 20 & \\
\hline & 10,00 & $\%$ & $0,0 \%$ & $20,6 \%$ & $31,0 \%$ & $14,3 \%$ & $16,7 \%$ & $20,0 \%$ & \\
\hline & $\mathrm{R} \$$ & $\mathrm{~N}$ & 2 & 6 & 4 & 2 & 4 & 18 & \\
\hline & 15,00 & $\%$ & $18,2 \%$ & $17,6 \%$ & $13,8 \%$ & $14,3 \%$ & $33,3 \%$ & $18,0 \%$ & \\
\hline & $\mathrm{R} \$$ & $\mathrm{~N}$ & 3 & 3 & 6 & 2 & 0 & 14 & \\
\hline & 20,00 & $\%$ & $27,3 \%$ & $8,8 \%$ & $20,7 \%$ & $14,3 \%$ & $0,0 \%$ & $14,0 \%$ & \\
\hline & $\mathrm{R} \$$ & $\mathrm{~N}$ & 3 & 2 & 2 & 3 & 1 & 11 & \\
\hline & 25,00 & $\%$ & $27,3 \%$ & $5,9 \%$ & $6,9 \%$ & $21,4 \%$ & $8,3 \%$ & $11,0 \%$ & \\
\hline & Mais & $\mathrm{N}$ & 1 & 7 & 0 & 3 & 1 & 12 & \\
\hline & $\begin{array}{l}\text { que } \mathrm{R} \$ \\
30,00\end{array}$ & $\%$ & $9,1 \%$ & $20,6 \%$ & $0,0 \%$ & $21,4 \%$ & $8,3 \%$ & $12,0 \%$ & \\
\hline & Não sei & $\mathrm{N}$ & 0 & 0 & 0 & 1 & 0 & 1 & \\
\hline & & $\%$ & $0,0 \%$ & $0,0 \%$ & $0,0 \%$ & $7,1 \%$ & $0,0 \%$ & $1,0 \%$ & \\
\hline \multirow[t]{2}{*}{ Total } & & $\mathrm{N}$ & 11 & 34 & 29 & 14 & 12 & 100 & \\
\hline & & $\%$ & $100,0 \%$ & $100,0 \%$ & $100,0 \%$ & $100,0 \%$ & $100,0 \%$ & $100,0 \%$ & \\
\hline
\end{tabular}

Tabela 4. Disposição a pagar em relação ao gênero

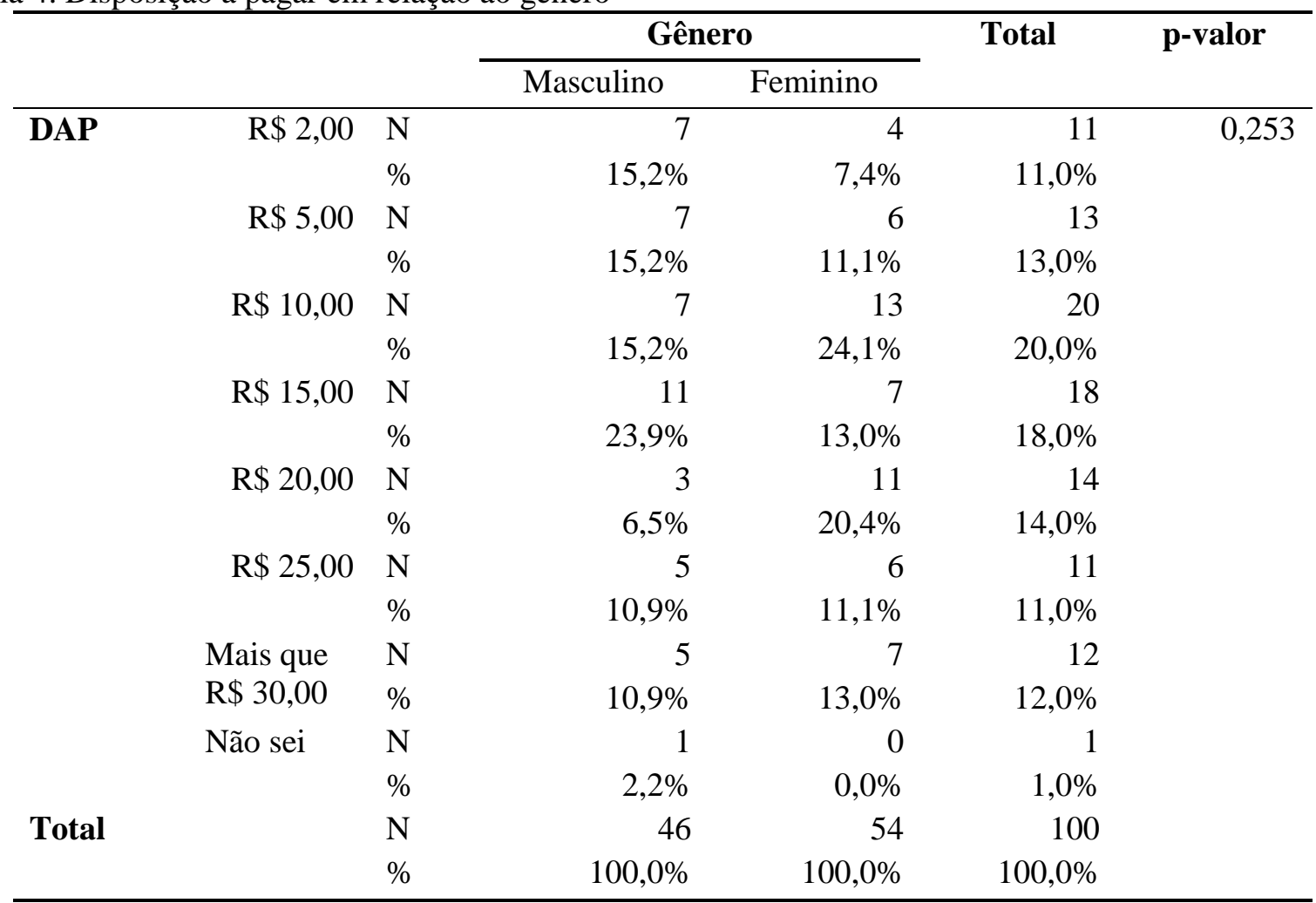

Sobre a relação local dos frequentadores (Local de Residência) versus Disposição A Pagar
(DAP), as informações da Tabela 5 expõem que a faixa etária influencia significativamente (p- 
valor $<0,05)$ o DAP, onde do total dos residentes no município, a maioria $(25,9 \%)$ está disposta a pagar mais que $\mathrm{R} \$ 30,00$. Por outro lado, os turistas tendem a pagar $\mathrm{R} \$ 5$ (22,2\% deles), $\mathrm{R} \$ 10(25,9 \%)$ ou R \$ 20 (25,9\%). Os veranistas, por sua vez, estão mais dispostos a pagar entre $\mathrm{R} \$ 15$ a $\mathrm{R} \$ 25$. Por fim, os excursionistas afirmam estar dispostos a pagar $\mathrm{R} \$ 10,00$ (36,4\% deles).

Tabela 5. Disposição a pagar em relação ao local de Residência

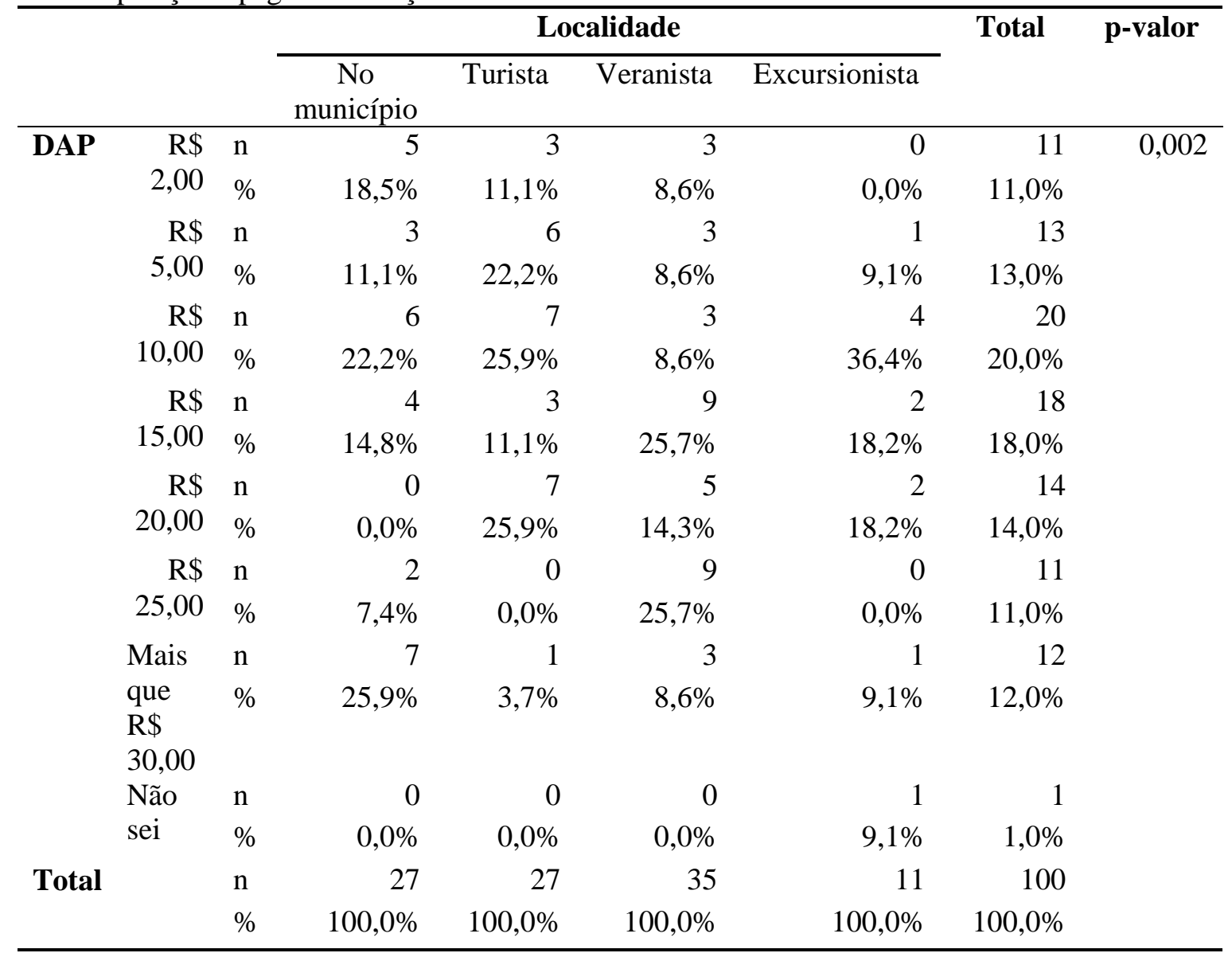

Acerca da escolaridade dos frequentadores, a Tabela 6 revela que a disposição a pagar independe ( $\mathrm{p}$-valor $>0,05)$ da escolaridade do entrevistado.

Ainda no estudo de Morgado et al. (2011) as principais variáveis independentes que mais influenciam a DAP são o grau de instrução, renda e a ocupação, uma vez que as mesmas possuem o maior coeficiente de correlação múltipla (R)2 $0,68 \% 0,45 \%$ e $0,46 \%$ respectivamente. No que tange a escolaridade e DAP. Araújo (2016) observou uma predominância dos indivíduos que afirmam possuir o Ensino Médio Completo (37\%), seguido das pessoas que declaram ter o Ensino
Superior Completo (21\%), não observando, desta forma, relação significativa do grau de escolaridade com o DAP. A tabela 6 consegue auxiliar na afirmação que o grau de escolaridade não alterou a DAP deste artigo, mostrando que a percepção sobre os serviços ambientais está mais nivelada e todos partilham a mesma linha de conhecimento seja na visão romântica ambiental ou na questão científica e/ou profissional dos ecossistemas, independente de grau de estudo e instrução.

A respeito da disposição a pagar sobre a renda familiar, a Tabela 7 contempla os dados tratados da análise.

Tabela 6. Disposição a pagar em relação à escolaridade 


\begin{tabular}{llrrrrrrrrr}
\hline & & $\begin{array}{c}\text { Fund. } \\
\text { Inc. }\end{array}$ & Fund & $\begin{array}{c}\text { Médio. } \\
\text { Inc. }\end{array}$ & $\begin{array}{c}\text { Médi } \\
\text { o }\end{array}$ & $\begin{array}{c}\text { Técni } \\
\text { co }\end{array}$ & $\begin{array}{c}\text { Superi } \\
\text { or }\end{array}$ & Pós & p- \\
valor
\end{tabular}

As informações da Tabela 7 mostram que a disposição a pagar independe ( $\mathrm{p}$-valor $>0,05)$ da renda salarial do entrevistado. Contudo, ressalta-se que o parque da Jaqueira está situado em uma das áreas mais nobres da cidade do Recife, herdando desta forma, o metro quadrado mais caro da cidade, logo, conclui-se que a grande maioria dos residentes do entorno possuem uma renda familiar alta. Todavia, verifica-se que pessoas que ganham entre um e dois salários mínimos, mostram-se mais dispostas a pagar para usufruir o Parque da Jaqueira.

Os maiores motivadores da não disposição a pagar (na probabilidade da não Disposição a Pagar - DAP), alegado pelos entrevistados estão elencados a não confiança sobre os recursos financeiros nas mãos de gestores públicos (1), os muitos impostos já pagos pelos contribuintes (2), e também foi dito que a questão da manutenção dos ecossistemas e obrigação do Estado (3).

Tabela7. Disposição a pagar em relação à Renda Familiar 


\begin{tabular}{|c|c|c|c|c|c|c|c|c|c|}
\hline & & & $\begin{array}{c}<\mathrm{R} \$ \\
937,00\end{array}$ & $\begin{array}{c}\mathrm{R} \$ \\
937,00 \mathrm{a} \\
\mathrm{R} \$ \\
1.874,00\end{array}$ & $\begin{array}{c}\mathrm{R} \$ \\
1.875,00 \\
\mathrm{a} \mathrm{R} \$ \\
2.811,00\end{array}$ & $\begin{array}{c}\mathrm{R} \$ \\
2.812,00 \\
\mathrm{a} \mathrm{R} \$ \\
3.748,00\end{array}$ & $\begin{array}{c}>\mathrm{R} \$ \\
3.749,00\end{array}$ & & $\begin{array}{c}\text { p- } \\
\text { valor }\end{array}$ \\
\hline \multirow[t]{16}{*}{ DAP } & \multirow{2}{*}{$\begin{array}{l}\mathrm{R} \$ \\
2,00\end{array}$} & $\mathrm{~N}$ & 3 & 1 & 2 & 4 & 1 & 11 & 0,180 \\
\hline & & $\%$ & $23,1 \%$ & $3,4 \%$ & $11,8 \%$ & $21,1 \%$ & $4,5 \%$ & $11,0 \%$ & \\
\hline & \multirow{2}{*}{$\begin{array}{l}\mathrm{R} \$ \\
5,00\end{array}$} & $\mathrm{~N}$ & 1 & 3 & 2 & 4 & 3 & 13 & \\
\hline & & $\%$ & $7,7 \%$ & $10,3 \%$ & $11,8 \%$ & $21,1 \%$ & $13,6 \%$ & $13,0 \%$ & \\
\hline & \multirow{2}{*}{$\begin{array}{l}\mathrm{R} \$ \\
10,00\end{array}$} & $\mathrm{~N}$ & 1 & 4 & 5 & 3 & 7 & 20 & \\
\hline & & $\%$ & $7,7 \%$ & $13,8 \%$ & $29,4 \%$ & $15,8 \%$ & $31,8 \%$ & $20,0 \%$ & \\
\hline & \multirow{2}{*}{$\begin{array}{l}\mathrm{R} \$ \\
15,00\end{array}$} & $\mathrm{~N}$ & 1 & 10 & 3 & 1 & 3 & 18 & \\
\hline & & $\%$ & $7,7 \%$ & $34,5 \%$ & $17,6 \%$ & $5,3 \%$ & $13,6 \%$ & $18,0 \%$ & \\
\hline & \multirow{2}{*}{$\begin{array}{l}\mathrm{R} \$ \\
20,00\end{array}$} & $\mathrm{~N}$ & 4 & 2 & 1 & 2 & 5 & 14 & \\
\hline & & $\%$ & $30,8 \%$ & $6,9 \%$ & $5,9 \%$ & $10,5 \%$ & $22,7 \%$ & $14,0 \%$ & \\
\hline & \multirow{2}{*}{$\begin{array}{l}\mathrm{R} \$ \\
25,00\end{array}$} & $\mathrm{~N}$ & 3 & 4 & 2 & 2 & 0 & 11 & \\
\hline & & $\%$ & $23,1 \%$ & $13,8 \%$ & $11,8 \%$ & $10,5 \%$ & $0,0 \%$ & $11,0 \%$ & \\
\hline & \multirow{4}{*}{$\begin{array}{l}\text { Mais } \\
\text { que R\$ } \\
30,00 \\
\text { Não sei }\end{array}$} & $\mathrm{N}$ & 0 & 5 & 2 & 3 & 2 & 12 & \\
\hline & & $\%$ & $0,0 \%$ & $17,2 \%$ & $11,8 \%$ & $15,8 \%$ & $9,1 \%$ & $12,0 \%$ & \\
\hline & & $\mathrm{N}$ & 0 & 0 & 0 & 0 & 1 & 1 & \\
\hline & & $\%$ & $0,0 \%$ & $0,0 \%$ & $0,0 \%$ & $0,0 \%$ & $4,5 \%$ & $1,0 \%$ & \\
\hline \multirow{2}{*}{\multicolumn{2}{|c|}{ Total. }} & $\mathrm{N}$ & 13 & 29 & 17 & 19 & 22 & 100 & \\
\hline & & $\%$ & $100,0 \%$ & $100,0 \%$ & $100,0 \%$ & $100,0 \%$ & $100,0 \%$ & $100,0 \%$ & \\
\hline
\end{tabular}

\section{Conclusão}

Os valores estimados pelos usuários para a manutenção e conservação do Parque servem de parâmetro para justificar o aporte de recursos financeiros em projetos que visem à manutenção das funções e dos serviços ambientais das árvores do parque, como também plantando mais árvores. É importante ressaltar que este artigo tratou dos serviços ambientais de regulação dos indivíduos arbóreos do parque da Jaqueira, lembrando que existem mais serviços ambientais no parque como de suporte cultural e provisão. Foram atribuídos diversos valores conforme visto na metodologia, sendo dado o valor de dez reais pelos serviços ambientais de regulação, demonstrando que a população está disposta a investir para a manutenção dos ecossistemas.

Por sua vez, a importância da área verde do parque reflete positivamente sobre o modo de vida dos cidadãos locais, visto que o lugar se torna propício á prática de esportes, leitura e lazer. Por outro lado, traz ônus para o mercado imobiliário local, já que o valor do imóvel na área construída sofre significativo valor por conta da área verde que circunda a região. Em relação ao microclima fica evidente que a área verde no parque ameniza o calor na cidade, uma das questões levantadas pelos frequentadores era a procura de áreas de sombras e paz que o local traz.
Para mais, os que deram a negativa para o pagamento pelos serviços ambientais, basearam-se na alta carga tributária já paga, ou na baixa confiabilidade em gestores públicos. Ainda assim, tais pessoas reconheciam a importância do meio ambiente e achando justos os esforços pela sua conservação.

Por fim, ressalta-se que este artigo não teve a finalidade de ter a valoração total como uma entrada no parque, e sim, o valor que cada frequentador estava disposto a pagar, pelos serviços ambientais de regulação que as árvores ofertam gratuitamente no parque, reconhecendo seu valor simbólico visando a conservação para as presentes e futuras gerações usufruírem.

\section{Agradecimentos}

Agradeço à CAPES (Coordenação de Aperfeiçoamento de Pessoal de Nível Superior) pela concessão da bolsa durante todo o período de realização do mestrado. Aos grupos de pesquisa SERGEO - Sensoriamento Remoto e Geoprocessamento, LAPIGA e NUVEM, pelo apoio a pesquisa e orientações. Agradeço ao IFMA e ao GEPAM - Grupo de Estudos e Pesquisas Ambientais do Maranhão pelo auxílio com a pesquisa e à FAPEMA - Fundação de Amparo à Pesquisa e ao Desenvolvimento Científico e Tecnológico do Maranhão pelo apoio à pesquisa. 


\section{Referências}

Altmann, A., Rech, U. A, 2009. Pagamento por serviços ambientais: imperativos jurídicos e ecológicos para a preservação e restauração das matas ciliares, 1 ed. EDUCS, Caxias do Sul.

Araújo, C.R.G., 2016. Turismo em Lagoas Costeiras e a Valoração Ambiental em OsórioRS. Dissertação (Mestrado). Caxias do Sul, UCS.

Araújo, M.A.R., 2012. Unidades de conservação no Brasil: a história de um povo em busca do desenvolvimento e da proteção da natureza, In: NEXUCS. (Org.), Unidades de conservação do Brasil: o caminho para gestão de resultados. Editora Rima, São Carlos, pp. 51-110.

Braga, R., 2009. Instrumentos para a gestão ambiental e de recursos hídricos, 1 ed. Universitária da UFPE, Recife.

Campos, R., 2007. A Relação entre o Imobiliário Turístico e o Meio Ambiente na RMR: Os espaços urbanos apropriados pela expansão do mercado imobiliário turístico e os impactos ambientais nas áreas litorâneas sul, 1 ed. Universitária da UFPE, Recife.

Constanza, R., 2008. Ecosystem services: multiple classifications systems are needed. Biological Conservation, 350-362.

Costa, L. S. D., 2003. Lugares em Casa Forte: onde residem as fortalezas dos lugares. Dissertação (Mestrado). Recife, UFPE.

Fávero, L.P., Belfiore, P., Silva, F.L., Chan, B.L, 2009. Análise de Dados: modelagem multivariada para tomada de decisões, 1 ed. Elsevier, Rio de Janeiro.

Freitas, E. População Economicamente Ativa no Brasil, 2016.2 Disponível: http://mundoeducacao.bol.uol.com.br/geografi a/populacao-economicamente-ativa-brasil. Acesso: 07 jan 2018.

Guedes, F.B., Seehusen, S.E., 2011. Pagamentos por serviços ambientais na mata atlântica: lições aprendidas e desafios, 1 ed. Biodiversidade, Brasília.

Leal, S.M.R., 2016. O Revés da Crise do Mercado Frente À Crise do Estado: A Retração da Acumulação Urbana nas Cidades Brasileiras, 2 2 ed. Universitária da UFPE, Recife.

Lima Junior, P.N., 2012. Efeitos de teoria: o debate acadêmico sobre os projetos urbanos e a legitimação de novas formas de produção do território, In: Oliveira, F.L.E.A. (org.), Grandes projetos metropolitanos: Rio de Janeiro e Belo Horizonte. Editora Letra Capital, Rio de Janeiro, pp. 24-45.

Macedo, S.S., Robba, F., 2002. Praças brasileiras, 1 ed. Edusp. São Paulo.
Malamut, M., 2014. Paisagismo: projetando espaços livres, 1 ed. Livro.com, Lauro de Freitas.

MILLENNIUM ECOSYSTEM ASSESSMENT., 2005. Ecosystems and Human Wellbeing: a Framework for Assessment, ed 1. Island Press, Washington.

Morgado, R.C., Abreu L.M., Réquia, W.J., Aravéchia, J.C., 2011.Valoração ambiental do parque ecológico de Usos Múltiplos Águas claras - DF: analisando a disposição a pagar dos usuários. Revista de estudos ambientais, 6-17.

Nusdeo, A. M. O., 2012. Pagamento por serviços ambientais: sustentabilidade e disciplina jurídica, 1 ed. Atlas, São Paulo.

Rech, A. U., 2011. O valor econômico e a natureza jurídica dos serviços ambientais, in: Rech, A. U. (org.), Direito e economia verde: natureza jurídica e aplicações práticas do pagamento por serviços ambientais, como instrumento de ocupações sustentáveis. Editora EDUCS, Caxias do Sul, pp. 12-49.

Silva, E.R.A.C., Santana, S.H.C., Melo, J.G. da S., Mendes, S.M.., Galvíncio, J.D., 2017. A transformação da natureza e as potencialidades do monitoramento ambiental na Lagoa Urbana Olho d'Água-PE: os desafios da complexa relação entre desenvolvimento urbano e a conservação de ambientes naturais. Guaju, 3264.

Tôsto, S.G., Pereira, L.C., Mangabeira, J.A.C., 2012. Serviços ecossistêmicos e serviços ambientais: conceitos e importância! PortalEcodebate. dez. 2012. Disponível: http://www.ecodebate.com.br/2012/12/13/servi cos-ecossistemicos-e servicosambientaisconceitos-e-importancia-artigo-de-sergiogomes-tosto-lauro-charletpereira- e-joaoalfredo-de-c-mangabeira. Acesso: 27 dez. 2017.

Viana, J. F. C., 2009. Valoração ambiental do parque ecológico e de uso múltiplo Olhos d' Água como subsídio à sua concessão. Dissertação (Mestrado). Brasília, Universidade Católica de Brasília.

Zukin, S., 2000. Paisagens do século XXI: notas sobre a mudança social e o espaço urbano, in: Arantes, A. (org.), $\mathrm{O}$ espaço da diferença. Campinas: Editora Papirus, Campinas, pp.104115. 